\title{
Editorial \\ Total Parenteral Nutrition-associated Cholestasis: Prematurity or Amino Acids?
}

\section{David H. Adamkin, MD}

Journal of Perinatology (2003) 23, 437-438. doi:10.1038/sj.jp.7210989

Immaturity of the gastrointestinal tract in very-low-birth-weight infants $(<1500 \mathrm{~g})$ (VLBW) precludes substantive nutritional support from enteral nutrition. Therefore, nearly all these infants are supported with parenteral nutrition (PN). In addition, PN has revolutionized the outcome for neonates and infants with intestinal failure either from congenital abnormalities or extensive gastrointestinal surgery. From a nutrition point of view, the liberal use of PN has been a huge success particularly in the VLBW infants.

Aggressive nutrition is a concept being proposed by neonatal nutritionists and is supported by recent studies. ${ }^{1,2}$ Theoretically, this means that the transfer from fetal to extrauterine life should proceed with minimal interruption of growth and development.

Amino acids administered from the first hours of life with a goal of providing fetal nutrient delivery rates to the neonate as soon as possible is a cornerstone of this strategy. This is key to avoid the period of early neonatal malnutrition. Several controlled studies have shown the efficacy and safety of amino acids initiated within the first 24 hours of life. ${ }^{3-7}$ There were no recognizable metabolic derangements including hyperammonemia, metabolic acidosis, or abnormal aminograms.

A strong argument for the early aggressive use of amino acids is the prevention of "metabolic shock". Concentrations of some key amino acids begin to plunge in the VLBW infant from the minute the cord is cut. This metabolic shock may trigger the starvation response, of which endogenous glucose production is a prominent feature. Irrepressible glucose production may be the cause of the so-called glucose intolerance that often limits the amount of energy that can be administered to the VLBW infant. It makes sense to smooth the metabolic transition from fetal to extrauterine life. Withholding PN for days, or even hours, means sending the infant unnecessarily into a metabolic emergency. Thus, the need for PN may never be more acute than right after birth. It is noteworthy that Rivera et al. made the surreptitious observation that glucose tolerance was substantially greater in the group receiving early amino acids; early amino acids may stimulate insulin secretion, which is consistent with the notion that forestalling the starvation response improves glucose tolerance. ${ }^{7}$

As with most therapies in neonatal intensive care, there are risks and complications. In this issue, Wright et al. discusses the increased incidence of PN-associated cholestasis (PNAC) in infants receiving two different pediatric amino-acid formulations.

Address correspondence and reprint requests to David H. Adamkin, University of Louisville School of Medicine, Dept. of Pediatrics, Kosair Charities Ped Center Ste 309, University of Louisville, Louisville, KY 40201, USA
The etiology of PN liver disease is unknown and is likely to be multifactorial. Many studies have noted the close relationship among the development of PNAC and birth weight, duration of PN, surgery, sepsis, days on PN before refeeding, and ECMO ${ }^{8-11}$

The increased incidence of PNAC in premature infants suggests that the development of disease may be related to immaturity of the neonatal liver. It is known that in premature infants the total bile salt pool is reduced. There is both diminished hepatic uptake and synthesis of bile salts as well as reduced enterohepatic circulation compared with full-term infants or adults. ${ }^{12}$ Sulfation, which is an important step in the solubilization of toxic bile salts such as lithocholic acid, is also deficient in the fetus and neonate. ${ }^{13}$ Therefore, it is likely that the liver and biliary system of the premature infant is more susceptible to toxic damage of any kind. $^{14,15}$

Animal studies have implicated amino acids in the production of cholestasis; whereas studies in human neonates suggest a direct effect of amino-acid infusions on the hepatocyte canalicular membrane. ${ }^{16}$ Previously, PN for preterm infants involved the administration of "general purpose" amino-acid solutions designed to meet the needs of adult patients. However, preterm neonatal protein requirements are not ideally approximated by these formulas. ${ }^{17}$ Furthermore, these general-purpose PN formulations, when administered to preterm infants, are reported to produce abnormal plasma amino-acid profices. ${ }^{18-22}$ These abnormalities are probably related to the immaturity of several enzymatic pathways in the preterm infant. ${ }^{6}$

Two intravenous amino-acid formulations specifically designed for infants and young children are currently marketed in the United States. Trophamine (Kendall-McGaw Laboratories, Irvine, $\mathrm{CA}$ ) is designed to produce plasma amino-acid concentrations approximating those of the healthy, breast-fed, term infant. ${ }^{23}$ Aminosyn-PF (Abbott Laboratories, North Chicago, IL) is designed to produce plasma amino-acid concentrations within a composite normal range identified in breast-fed infants and in infants fed general-purpose amino-acid solutions ${ }^{24-29}$ Clinical studies comparing these neonatal amino-acid solutions with various general purpose formulations raise concerns about the safety of elevated plasma concentrations of phenylalanine, methionine, and glycine, as well as efficacy questions centered on low plasma concentrations of tyrosine, taurine, cyst(e)ine, and the branched chain amino acids observed in neonates receiving solutions designed for adults. Adamkin et al. ${ }^{30}$ in a multicenter study compared the two pediatric intravenous amino-acid solutions in preterm infants and found the rate of weight gain, nitrogen balance, and nitrogen retention to be similar. Seven-day plasma aminograms for both solutions also compared favorably with those from enterally fed preterm infants in the literature. ${ }^{30}$ However, it did not address specifically the issue of cholestasis, although liver function tests were similar after the 7 day infusion. Forchelli et al. ${ }^{31}$ 
reported that the two pediatric amino-acid solutions were similar in the incidence of PNAC observed in 70 infants $<1$ year who received PN for at least 14 days. Now, Wright et al. report PNAC developing more quickly as well as more severe and prolonged with Aminosyn$\mathrm{PF}$ vs trophamine in a retrospective review. ${ }^{32}$

The prevention or reversal of PNAC is the second cornerstone of aggressive nutrition, the early initiation of enteral feedings. Early enteral feeding maintains the integrity of the intestine, promotes better immune responses, and diminishes bacterial translocation. The gallbladder is stimulated to empty and bile salt metabolism becomes more normal.

As with all therapies in neonatal intensive care, we must remain vigilant and continue to re-evaluate our progress as well as failures. Is it prematurity or the amino-acid solution? Only time will tell. Staying aggressive with nutrition remains a good idea.

\section{References}

1. Wilson DC, Carins P, Halliday HL, et al. Randomized controlled trial of an aggressive nutritional regimen in very low birth weight infants. Arch Dis Child Fetal Neonatal Ed 1997;77:4F-11F.

2. Pauls J, Bauer K, Versmold H. Postnatal body weight curves for infants below $1000 \mathrm{~g}$ birth weight receiving early enteral and parenteral nutrition. Eur J Pediatr 1998;157:416-21.

3. Bauer K, Bovermann G, Roithmaier A, et al. Body composition, nutrition, and fluid balance during the first two weeks of life in preterm neonates weighting less than 1500 grams. J Pediatr 1991;118:615-20.

4. van Lingen RA, van Goudoever JB, Luijendijk IHT, et al. Effects of early amino acid administration during total parenteral nutrition on protein metabolism in preterm infants. Clin Sci 1992;82:199-203.

5. Murdock N, Crighton A, Nelson LM, et al. Low birthweight infants and total parenteral nutrition immediately after birth. II. Randomized study of biochemical tolerance of intravenous glucose, amino acids, and lipid. Arch Dis Child 1995;73:F8-12.

6. Poindexter BB, Karn CA, Ahlrichs JA, et al. Amino acids suppress proteolysis independent of insulin throughout the neonatal period. Am J Physiol 1997;272:R592-9.

7. Clark SE, Karn CA, Ahlrichs JA, et al. Acute changes in leucine and phenylalanine kinetics produced by parenteral nutrition in premature infants. Pediatr Res 1997;41:568-74.

8. Beale EF, Nelson RM, Bucciarelli RL, et al. Intra hepatic cholestasis associated with parenteral nutrition in premature infants. Pediatrics 1979;64:342.

9. Sondheimer JM, Bryan H, Andrews W, Forstener GG. Cholestatic tendencies in premature infants on and off parenteral nutrition. Pediatrics 1978;62:984.

10. Rager R, Finegold MJ. Cholestasis in immature newborn infants: is parenteral alimentation responsible? J Pediatr 1975;86:264.

11. Benjamin DR. Hepatobiliary dysfunction in infants and children associated with long-term total parenteral nutrition in clinico-pathologic study. Am J Clin Pathol 1981;76:276.

12. Watkins JB, Szczepanik P, Gould JB, Lester R. Bile salt metabolism in the human premature infant. Gastroenterology 1975;69:706.
13. Watkins JB. Placental transport bile acid conjugation and sulphation in the fetus. J Pediatr Gastroenterol Nutr 1983;2:365.

14. Palmer RH, Hruban Z. Production of bile duct hyperplasia and gallstones by lithocholic acid. J Clin Invest 1964;45:1255.

15. Miyai K, Price VM, Fisher MM. Bile acid metabolism in mammals. Ultrastructural studies on the intrahepatic cholestasis induced by lithocholate and chenodeoxycholic acids in the rat. Lab Invest 1971;24:292.

16. Blac DD, Sutle EA, Whitington PF, Whitington GL, Korones SDE. The effect of short term total parenteral nutrition on hepatic function in the human neonate; a prospective randomized study demonstrating alteration of hepatic canalicular function. J Pediar 1981;99:445.

17. Brown MR, Thunber BJ, Golub L, Maniscalo WM, Cox C, Shapiro DL. Decreased cholestasis with enteral instead of intravenous protein in the very low birth weight infant. J Pediatr Gastroenterol Nutr 1989;9:21.

18. Adamkin DH, Sims A, Radmacher P. Plasma amino acids in premature neonates receiving a pediatric amino acid formulation in containing taurine, glutamate and aspartate. J Parenter Enteral Nutr 1985;9:119.

19. Chessex P, Zebiche H, Pineault M, et al. Effect of amino acid composition of parenteral solutions on nitrogen retention and metabolic response in very low birthweight infants. J Pediatr 1985;106:111-7.

20. Helms RA, Christensen JL, Mauer EC, Storm MC. Comparision of a pediatric versus standard amino acid formulation in preterm neonates requiring parenteral nutrition.J Pediatr 1987;110:466-70.

21. Kanaya S, Naic 0 , Harads T, et al. Total parenteral nutrition with a new amino acid solution for infants. J Pediatr Gastroenterol Nutr 1984;3:440-5.

22. Raiha NCR. Biochemical basis for nutritional management of preterm infants. Pediatrics 1974;53:147-56.

23. Heird WC, Dell RB, Helms RA, et al. Evaluation of an amino acid mixture designed to maintain normal plasma amino acid patterns in infants and children requiring parenteral nutrition. Pediatrics 1987;80:401-8.

24. Filer LJ, Stegink LD, Chandramouli B, et al. Effect of diet on plasma aminograms of low-birth-weight infants. Am J Clin Nutr 1977;30:1036-43.

25. Pohlandt F. Plasma amino acid concentrations in newborn infants breastfed ad libitum. J Pediatr 1978;92:614-6.

26. Mertes S, editor. Pediatric Clinical Chemistry. Vol. 28. Washington: American Association for Clinical Chemistry; 1977. p. 31.

27. Sober HA, editor Hand book of Biochemistry, Selected Data for Molecular Biology. Cleveland, OH: The Chemical Rubber Company; 1968. p. B-55.

28. Andersen GE, Bucher D, Friishansen B, et al. Plasma amino acid concentrations in new born infants during parenteral nutrition. J Parenter Enteral Nutr 1983;7:369-73.

29. Thom JC, et al. The effect of intravenous amino acid concentration during total parenteral nutrition in infants with necrotizing enterocolitis.S Afr Med J 1981;59:946-9.

30. Adamkin DH, McClead Jr RE, Desai NS, McCulloch KM, Marchildon MB. Comparision of two neonatal intravenous amino acid formulations in preterm infants: a multicenter study. J Perinatol 14991;11:375-82.

31. Forchielli ML, Gura KM, Sandler R, Lo C. Aminosyn PF or trophamine: which provides more protection from cholestasis associated with total parenteral nutrition? J Pediatr Gastroenterol Nutr 1995;21:374-82.

32. Wright K, Ernst KD, Gaylord MS, Dawson JP, Burnette TM. Increased incidence of parenteral nutrition-associated cholestasis with aminosyn $\mathrm{PF}$ compared to trophamine. J Pediatr 2003;23:444-450. 